\title{
Adaptation in fire-prone landscapes: interactions of policies, management, wildfire, and social networks in Oregon, USA
}

\author{
Thomas A. Spies $^{1}$, Robert M. Scheller $^{2}$ and John P. Bolte ${ }^{3}$
}

\begin{abstract}
This editorial introduces the special feature on the social-ecological system of a fire-prone forest landscape in Oregon, USA. Research into social-ecological systems of fire-frequent landscapes is in its infancy and this special feature highlights one of the first attempts to understand a fire-dependent forest landscape from this perspective. An agent-based landscape modeling framework, Envision, was the primary tool for the research. The papers in this special feature examine three major questions: (1) What is the landscape structure of forest conditions, fire regimes, ownerships, and attitudes toward fire and forest management?; (2) How are social networks of the study region structured and how might they influence attitudes and actions of landowners?; (3) How do land management policies, institutions, and decisions interact to influence future fire occurrence, biodiversity, and ecosystem services? The findings of the empirical research and simulation modeling reveal how the high ecological and social (e.g., landownership and management goals) diversity of the region contributes to very different fire potentials, attitudes, and management approaches across space. The social network analysis reveals that the social network is divided into fire protection and fire restoration subnetworks that only a few organizations were able to bridge. The simulation modeling shows how difficult it can be to affect fire behavior across large areas, and what the trade-offs of different management actions might be in terms of ecosystem services and fire risk. The special feature also includes papers that examine how social science research is influenced by the use of an agent-based model, and what has been learned about the process of conducting social-ecological research and engaging with stakeholders with the goal of improving understanding of and adaptation to fire-frequent landscapes.
\end{abstract}

Key Words: forests; social-ecological systems; wildfire risk; wildland urban interface

\section{INTRODUCTION}

The footprint of society has been expanding rapidly into fireprone landscapes over the last century with many undesirable outcomes: more and more losses of homes and lives to wildfire, ballooning fire-fighting costs, and reduced resilience of forests to fire and climate change (Hammer et al. 2007, Fischer et al. 2016). Decades of fire policies that have effectively excluded fire from historically fire-frequent forests have often increased the size and severity of fires relative to how fires burned historically. With increasing warming, fire is returning to forests and landscapes where it was much more frequent in the past, though it is still less frequent than it was historically. However, current landscapes are no longer fire-adapted ecosystems; they having been altered by many years of fire exclusion, forest management, and housing development. And, the humans living in them do not have a culture of using and living with fire as did native peoples who occupied many of these landscapes when fire was frequent. The intersection of wildfire and human values (both economic and ecological) poses significant challenges for society, policy makers, and land managers. Some have termed the situation a socialecological pathology: a set of interrelated social and ecological conditions and processes that deviate from what is considered healthy or desirable and reinforce that outcome through positive feedback loops (Fischer et al. 2016). The problem can be reduced to two broad, not mutually exclusive, response options: (1) mitigating wildfire behavior and effects through land management to reduce or exclude fire effects; and (2) accepting and adapting to the occurrence of wildfire through changes in practices (e.g., fire wise) policies and attitudes (e.g. learning to live with fire).
It is clear that most fire-prone landscapes are social-ecological systems but only recently have scientists begun to call for socialecological approaches to understanding these systems (Spies et al. 2014, Moritz et al. 2014, Fischer et al. 2016). The challenges of understanding and effectively managing social-ecological systems in fire-prone landscapes lie in system complexity, which has numerous components: (1) ecological variability in fire regimes and effects; (2) both positive and negative effects of wildfire, e.g. ,good fire and bad fire, relative to human values and land management objectives; (3) spatial and temporal lags in feedbacks between the social and ecological systems that control risk perception and fire outcomes; (4) spatio-temporal interactions of management, vegetation, and fire that make it difficult to understand effects of fire management practices across scales; (5) role of history in controlling biophysical conditions and perceptions of fire; (6) differences in scientific disciplines that make integration of ecological and social sciences difficult; and (7) communicating science to stakeholders and developing science based policies and practices in a political world where science often plays a minor role.

Given that research into social-ecological systems in fire-frequent landscapes is in its infancy (Moritz et al. 2014), many questions remain unanswered, the questions themselves are still evolving, and there are few established standards for research approaches. In this special feature we make one of the first attempts to understand a fire-dependent region as a social-ecological system. We couple an agent-based approach with landscape-level process models to structure our research, but the findings go well beyond model results. For example, basic information about human decision making and factors influencing management goals and

${ }^{1}$ USDA Forest Service Pacific Northwest Research Station, Corvallis, OR, ${ }^{2}$ Dept. Forestry and Environmental Resources, North Carolina State

University, ${ }^{3}$ Oregon State University, College of Agricultural Sciences, Biological and Ecological Engineering 
approaches had to be discovered in order to build and parameterize the model.

Our initial emphasis was on determining the ecological and social structure of this heterogeneous region in order to understand spatial and nonspatial variation and provide information to the landscape model. We could not understand our system and its interactions without first characterizing its components, both ecological and social, at appropriate spatial and process scales. Our landscape model was the lens through which we framed and evaluated our system; other models or approaches might result in a different framing and findings (Kline et al. 2017). Our overarching questions were the following:

1. What is the landscape structure (variety, size, and spatial pattern) of forest conditions, fire regimes, ownerships, and attitudes toward fire and forest management?

2. How are social networks of the study region structured and how might they influence attitudes and actions of landowners?

3. How do land management policies, institutions, and decisions interact (including feedbacks) to influence future fire outcomes, biodiversity, and ecosystem services?

\section{QUESTION 1. WHAT IS THE LANDSCAPE STRUCTURE OF FOREST CONDITIONS, FIRE REGIMES, OWNERSHIPS, AND ATTITUDES TOWARD FIRE AND FOREST MANAGEMENT?}

Identifying the ecological and social units of a system is one of the first steps in building an understanding of social-ecological systems and their interactions. This step is essential for models that focus on interactions among heterogeneous decision makers ("agent-based models"), i.e., people or organizations that make decisions to alter the vegetation of their parcels based in part on knowledge of fire hazard on the parcel and in surrounding parcels or on information they gain from people and organizations with whom they communicate. The landscape is also composed of patches of vegetation with variable growth that interact and dynamically serve as sources or sinks for fire.

The ecological and social spatial structures of a region can play a large role in determining system behavior and responses of agents and ecosystem services to system dynamics (Spies et al. 2017). For example, in our study area east of the Cascade Mountains, forest types and fire regimes vary strongly along topographic gradients that run from west to east. In the western portion of this area wilderness areas dominate, forests are cool and moist, and wildfires are historically infrequent but typically burn with high severity. Management in wilderness areas is very limited. Moving further east, federal forest lands dominate; fires were historically more frequent, and fire exclusion has resulted in fuel accumulations that can lead to high-severity fire under extreme weather or reduce fire spread under more moderate weather. Private forest lands and human settlements occur in the drier forest types that extend to arid lands (nonforested) on the eastern margin of the region. Landownership of the dry forests is still dominated by federal owners but large industrial owners, state forest owners, and small family forest owners are concentrated in these areas. The wildland-urban interface (WUI) is a fairly small proportion of this larger federal-private forest landscape and concentrated around cities and highways in the drier environments (Olsen et al. 2017).

Landowner perspectives on fire and forests are quite diverse. They range from private land owners and state land owners who do not use prescribed fire and focus on excluding fire to protect timber resources and homes (Charnley et al. 2017), to federal managers who use prescribed fire to reduce risk and manage for both protection from fire and for restoring forest ecosystems that are dependent on frequent fire (Kline et al. 2017). Tribal forest owners have a similar approach to federal forest owners but tribal lands have a higher incidence of human ignitions of wildfire compared to other ownerships.

The result of the patterns on this landscape are that the management actions of a single landowner (the U.S. Forest Service) dominate the landscape. Federal management is concentrated on dry forests (outside the wilderness areas) that have been altered by fire exclusion. The WUI is a relatively small part of this landscapes but gets a disproportionate share of policy interest, e.g. from the U.S. Forest Service, given the high level of human values that occur there (Olsen et al. 2017). The homeowners and private forest owners in this landscape pay considerable attention to fire hazard conditions on federal lands. Many of these owners take actions to reduce risk to their homes, or conduct forest thinning and fuel reduction, especially if they have experienced a wildfire event or are familiar with their community's wildfire protection plan (Charnley et. al. 2017, Olsen et al. 2017, Wolters et al. 2017).

Steen-Adams et al. (2017) examined the historical trends in, and influences on, wildfire policy among the large owners (U.S. Forest Service, corporate, and tribal) in the study area. They found that attitudes and policies toward fire have changed at different rates and degrees among these owners. Policies have become more centralized over the last 100 years but in recent years some owners have reevaluated their objectives and approaches and given mangers more flexibility to adopt new objectives and practices. They also found that informal institutions, e.g. cultural norms, and institutional history influenced wildfire management adaptation. The timing of institutional change matters and depends on synchrony of evolution of informal and formal institutions. Asynchronous change in policies and cultural norms can delay adaptation to wildfire.

\section{QUESTION 2. HOW ARE SOCIAL NETWORKS STRUCTURED AND HOW MIGHT THEY INFLUENCE ATTITUDES AND ACTIONS OF LANDOWNERS?}

Social networks play an important role in structuring interactions among institutions and promoting learning and adaptation to living with fire risk. Our goal was to learn how social systems influence landscape conditions and vice versa. Such knowledge is needed if we are to incorporate those processes in agent-based models and to identify possible ways to increase the adaptive capacity of communities. Our study area contains a rich social landscape of organizations that were concerned with wildfire risk. However, the organizations did not form a single cohesive network and were largely divided into those that worked primarily with other organizations that shared their values, i.e., those that worked either on fire protection or forest restoration (Fischer and Jasny 2017). A few organizations, e.g., U.S. Forest Service and The 
Nature Conservancy, were in a position to bridge the divide between groups and are well positioned to increase the adaptive capacity of the network.

A social network analysis was conducted at the scale of a two rural communities (Jacobs and Cramer 2017) and addressed how communities perceive climate change and wildfire risk and where they get their information. They found that perceptions of climate change were driven more by social and cultural systems, e.g., trust in government, than from general information about the scientific basis or global impacts of climate change. They found that using local concerns such as wildfire risk could be a better way to frame the problem of adaptation to climate change than focusing on climate change per se. Finally, they found that community-based adaptation may be enhanced through stronger local media efforts and dialog between residents and existing institutions.

\section{QUESTION 3. HOW DO LAND MANAGEMENT POLICIES AND INSTITUTIONS, AND ACTOR DECISIONS INTERACT, INCLUDING FEEDBACKS, TO INFLUENCE FIRE OUTCOMES, BIODIVERSITY, AND ECOSYSTEM SERVICES?}

We examined outcomes of alternative approaches to managing for fire protection and restoration in this large landscape using the "Envision" modeling framework (Bolte et al. 2007). Envision integrated processes of forest succession and fuel dynamics, wildfire ignition and spread, and forest management to evaluate metrics including fire occurrence, severity, hazard (severity potential), exposure of homes to wildfire, smoke, timber harvest volume, forest resilience, carbon, and habitat area for several wildlife species. We modeled landowner behavior of owners in two ways (Kline et al. 2017). For large landowners, we assumed landowners made management decisions to meet annual targets for wood volume harvested and/or acres of fuel treatment that are influenced by constraints (federal land allocation, laws/ regulations, and fire history) and preferences for certain vegetation conditions in a parcel and the surrounding area. For family forest owners and homeowners, we used probabilistic models of undertaking timber harvest and fuel reduction treatments based on fire hazard in the surrounding landscape and/ or past occurrence of fire near an ownership parcel. To examine the combined effects of management, ecological processes, and stochastic wildfire disturbances across the entire landscape, we developed a simple set of scenarios that varied in level of management intensity and projected the landscape 50 years into the future.

Spies et al. (2017) found that increased treatments on federal lands (doubling of current rates) had relatively little effect on amount of high-severity fire predicted by the model in an average fire year but it did substantially reduce potential high-severity fire hazard across the landscape. These finding could be explained by the fact that wildfire is still a relatively rare occurrence and even a doubling of treatment area is not sufficient to significantly increase the likelihood that wildfires will encounter a treatment area during the time period (about 10 years) over which they reduce fuels in the study landscape. This study also found that there were tradeoffs among metrics, e.g., carbon and wildlife habitat, such that some components were favored, e.g., habitat for species that use open forests, by more active management while others, e.g., carbon and habitat for dense forest species, were favored by less management.
Barros et al. (2017) found that wildfire behavior did not change over time (50 years) under any management scenario, suggesting that current rates of wildfire, although they are a general social concern, are not high enough to cumulatively change landscapelevel fuel conditions. Efforts to substantially increase rates of treatment on federal lands, e.g., two to three times, had some effect on fire occurrence but could not be sustained because of constraints, e.g., vegetation conditions or land management allocation, on where treatments could be placed.

Ager et al. (2017) simulated increases in fire occurrence that may occur under climate change. They found that area burned in a given simulation year was reduced about $18 \%$ per unit area burned within the prior five years averaged across all scenarios. The reduction in area burned was accompanied by substantially lower fire severity, and a vegetation shift to open forest and grass-shrub conditions at the expense of older forests. The short-term $(<10$ years) negative feedbacks stemmed from fires encountering recently burned areas. Evidence of longer term positive feedbacks was also seen, resulting from fire-induced accelerated succession, where the landscape changed from relatively stable mature vegetation states to younger successional stages that have rapid transitions to increasingly flammable conditions.

Charnley et al. (2017) used Envision to examine approaches to adaptation between large federal owners and large corporate owners. They found that large corporate owners do not have resilient forests because of recent past management and their use of forest protection strategies that attempt to exclude wildfire and prescribed fire (the "fortress" approach). Under the fortress approach the lack of prescribed fire leads to an increase in surface fuels in the years postharvest. Prescribed fire is typically not used by large corporate owners because it can damage existing trees (reducing timber value) and carries some risks associated with escaped prescribed fires. They also found that, contrary to some perceptions, federal forests were more resilient to wildfire as a result of the use of prescribed fire and the presence of large trees, which are more resistant to fire when it does occur. They conclude that heterogeneity in social-ecological systems did not generate social-ecological resilience, and that better understanding of the connections among social, economic, and ecological components can identify constraints, e.g., economic and institutional, that affect social-ecological resilience to natural disturbances.

Our study provided one of the first formal characterizations of the complexities, e.g., heterogeneity and feedbacks, of a socialecological system in a fire-prone landscape. It demonstrates why development of adaptation strategies and practices in these disturbance prone landscapes can be so difficult. It also points out possible areas, e.g., expanding social networks, bridging institutional barriers, and increasing understanding of the ecological trade-offs of different management actions, where progress could be made in promoting more adaptive approaches to living in fire-prone landscapes.

Throughout our study we engaged with stakeholders to learn about their views but also to share our findings and engage in joint learning (Shindler et al. 2017) and that process has continued after the formal end of this project. Engaging stakeholders with a model about complex systems is very challenging from a number of perspectives (Gustafson et al. 2007) but above all requires time and commitment that may be beyond the capacity of many scientists. Although many scientists do not engage in such 
activities, it is increasingly important that they do given the significance and complexity of our environmental problems.

We also learned much about integrating ecological and social methods and knowledge in the pursuit of understanding social and ecological systems (Kline et al. 2017, Shindler et al. 2017). Those lessons include engaging with stakeholders early in the process and having a robust research process that includes identifying key members of the team who have interest and time to devote to integration and to team processes that promote communication and internal peer review. Finally, it should be remembered that integration of social and ecological sciences involves bridging large divides in how science is conducted in different disciplines. Distilling complex human systems into simulation models inevitably involves simplifications that may eliminate key dimensions of social and ecological systems and early selection of models and methods will set the bounds on the questions that can be addressed (Kline et al. 2017). There are many pathways to research about social-ecological systems. We expect that a diversity of interdisciplinary approaches will lead to the greatest understanding of these systems.

Responses to this article can be read online at: http://www.ecologyandsociety.org/issues/responses. $\mathrm{php} / 10079$

\section{Acknowledgments:}

This research was funded by the National Science Foundation, Coupled Human and Natural Systems Program (NSF Grant CNH-1013296), the USDA Forest Service, PNW Research Station. We thank Eric White for comments on an earlier version of this manuscript.

\section{LITERATURE CITED}

Ager, A. A., A. M. G. Barros, H. K. Preisler, M. A. Day, T. A. Spies, J. D. Bailey, and J. P. Bolte. 2017. Effects of accelerated wildfire on future fire regimes and implications for the United States federal fire policy. Ecology and Society 22(4):12. [online] URL: http://dx.doi.org/10.5751/ES-09680-220412

Bolte, J. P., D. W. Hulse, S. V. Gregory, and C. Smith. 2007. Modeling biocomplexity - actors, landscapes, and alternative futures. Environmental Modeling and Software 22(5):570-579. http://dx.doi.org/10.1016/j.envsoft.2005.12.033

Barros, A. M. G., A. A. Ager, M. A. Day, H. K. Preisler, T. A. Spies, E. White, R. Pabst, K. A. Olsen, E. Platt, J. D. Bailey, and J. P. Bolte. 2017. Spatiotemporal dynamics of simulated wildfire, forest management, and forest succession in central Oregon, USA. Ecology and Society 22(1):24. http://dx.doi.org/10.5751/ ES-08917-220124

Charnley, S., T. A. Spies, A. M. G. Barros, E. M. White, and K. A. Olsen. 2017. Diversity in forest management to reduce wildfire losses: implications for resilience. Ecology and Society 22(1):22. http://dx.doi.org/10.5751/ES-08753-220122

Fischer, A. P., and L. Jasny. 2017. Capacity to adapt to environmental change: evidence from a network of organizations concerned with increasing wildfire risk. Ecology and Society 22 (1):23. http://dx.doi.org/10.5751/ES-08867-220123

Fischer, A. P., T. A. Spies, T. A. Steelman, C. Moseley, B. R. Johnson, J. D. Bailey, A. A. Ager, P. Bourgeron, S. Charnley, B. M. Collins, and J. D. Kline. 2016. Wildfire risk as a socioecological pathology. Frontiers in Ecology and the Environment 14 (5):276-284. http://dx.doi.org/10.1002/fee.1283

Gustafson, E. J., B. R. Sturtevant, and A. Fall. 2007. A collaborative, iterative approach to transferring modeling technology to land managers. Pages 43-64 in A. H. Perera, L. J. Buse, and T. R. Crow, editors. Forest landscape ecology: transferring knowledge to practice. Springer, New York, New York, USA. http://dx.doi.org/10.1007/978-0-387-34280-1

Hammer, R. B., V. C. Radeloff, J. S. Fried, and S. I. Stewart. 2007. Wildland-urban interface housing growth during the 1990s in California, Oregon, and Washington. International Journal of Wildland Fire 16(3):255-265.

Jacobs, D. B., and L. A. Cramer. 2017. Applying information network analysis to fire-prone landscapes: implications for community resilience. Ecology and Society 22(1):52. http://dx.doi. org/10.5751/ES-09119-220152

Kline, J. D., E. M. White, A. P. Fischer, M. M. Steen-Adams, S. Charnley, C. S. Olsen, T. A. Spies, and J. D. Bailey. 2017. Integrating social science into empirical models of coupled human and natural systems. Ecology and Society 22(3):25. http:// dx.doi.org/10.5751/ES-09329-220325

Moritz, M. A., E. Batllori, R. A. Bradstock, A. M. Gill, J. Handmer, P. F. Hessburg, J. Leonard, S. McCaffrey, D. C. Odion, T. Schoennagel, and A. D. Syphard. 2014. Learning to coexist with wildfire. Nature 515(7525):58-66. http://dx.doi.org/10.1038/ nature 13946

Olsen, C. S., J. D. Kline, A. A. Ager, K. A. Olsen, and K. C. Short. 2017. Examining the influence of biophysical conditions on wildland-urban interface homeowners' wildfire risk mitigation activities in fire-prone landscapes. Ecology and Society 22(1):21. https://doi.org/10.5751/ES-09054-220121

Shindler, B., T. A. Spies, J. P. Bolte, and J. D. Kline. 2017. Integrating ecological and social knowledge: learning from CHANS research. Ecology and Society 22(1):26. http://dx.doi. org/10.5751/ES-08776-220126

Spies, T. A., E. White, A. Ager, J. D. Kline, J. P. Bolte, E. K. Platt, K. A. Olsen, R. J. Pabst, A. M. G. Barros, J. D. Bailey, S. Charnley, A. T. Morzillo, J. Koch, M. M. Steen-Adams, P. H. Singleton, J. Sulzman, C. Schwartz, and B. Csuti. 2017. Using an agent-based model to examine forest management outcomes in a fire-prone landscape in Oregon, USA. Ecology and Society 22(1):25. http:// dx.doi.org/10.5751/ES-08841-220125

Spies, T. A., E. M. White, J. D. Kline, A. P. Fischer, A. Ager, J. Bailey, J. Bolte, J. Koch, E. Platt, C. S. Olsen, D. Jacobs, B. Shindler, M. M. Steen-Adams, and R. Hammer. 2014. Examining fire-prone forest landscapes as coupled human and natural systems. Ecology and Society 19(3):9. http://dx.doi.org/10.5751/ ES-06584-190309

Steen-Adams, M. M., S. Charnley, and M. D. Adams. 2017. Historical perspective on the influence of wildfire policy, law, and 
informal institutions on management and forest resilience in a multiownership, frequent-fire, coupled human and natural system in Oregon, USA. Ecology and Society 22(3):23. http://dx.doi. org/10.5751/ES-09399-220323

Wolters, E. A., B. S. Steel, D. Weston, and M. Brunson. 2017. Determinants of residential firewise behaviors in central Oregon. Social Science Journal 54(2):168-178. http://dx.doi.org/10.1016/j. soscij.2016.12.004 